LAWRENCE LIVERMORE N A T IO N A L LABORATORY

\section{The National Ignition Facility: Laser Performance and First Experiments}

Craig R. Wuest, Edward I. Moses

September 21, 2004

16th ANS Topical Meeting on the Technology of Fusion Energy

Madison, WI, United States

September 14, 2004 through September 16, 2004 
This document was prepared as an account of work sponsored by an agency of the United States Government. Neither the United States Government nor the University of California nor any of their employees, makes any warranty, express or implied, or assumes any legal liability or responsibility for the accuracy, completeness, or usefulness of any information, apparatus, product, or process disclosed, or represents that its use would not infringe privately owned rights. Reference herein to any specific commercial product, process, or service by trade name, trademark, manufacturer, or otherwise, does not necessarily constitute or imply its endorsement, recommendation, or favoring by the United States Government or the University of California. The views and opinions of authors expressed herein do not necessarily state or reflect those of the United States Government or the University of California, and shall not be used for advertising or product endorsement purposes. 


\title{
THE NATIONAL IGNITION FACILITY: LASER PERFORMANCE AND FIRST EXPERIMENTS
}

\author{
Edward I. Moses, Craig R. Wuest \\ Lawrence Livermore National Laboratory \\ P.O. Box 808 L-466 \\ Livermore, CA 94551 \\ (925) 423-9624 \\ moses1@1lnl.gov
}

The National Ignition Facility (NIF) at the Lawrence Livermore National Laboratory is a stadium-sized facility containing a 192-beam, 1.8-Megajoule, 500-Terawatt, ultraviolet laser system together with a 10-meter diameter target chamber with room for nearly 100 experimental diagnostics. NIF will be the world's largest and most energetic laser experimental system, providing a scientific center to study inertial confinement fusion (ICF) and matter at extreme energy densities and pressures. NIF's energetic laser beams will compress fusion targets to conditions required for thermonuclear burn, liberating more energy than required to initiate the fusion reactions. Other NIF experiments will study physical processes at temperatures approaching $10^{8} \mathrm{~K}$ and $10^{11}$ bar, conditions that exist naturally only in the interior of stars, planets and in nuclear weapons. NIF has successfully activated, commissioned, and utilized the first four beams of the laser system to conduct over 300 shots between November 2002 and August 2004. NIF laser scientists have established that the laser meets nearly all performance requirements on a per beam basis for energy, uniformity, timing, and pulse shape. Using these four beams, ICF and highenergy-density physics researchers have conducted a number of experimental campaigns resulting in high quality data that could not be reached on any other laser system. We discuss the successful NIF Early Light Program including details of laser performance, examples of experiments performed to date, and recent advances in the ICF Program that enhance prospects for successful achievement of fusion ignition on NIF.

\section{INTRODUCTION}

The National Ignition Facility (NIF) under construction at the Lawrence Livermore National Laboratory (LLNL) will be a U. S. Department of Energy and National Nuclear Security Administration (NNSA) national center to study inertial confinement fusion and the physics of extreme energy densities and pressures. It will be a vital part of the NNSA Stockpile Stewardship Program (SSP), which ensures the reliability and safety of U. S. nuclear weapons. In NIF, up to 192 extremely powerful laser beams will compress deuterium-tritium fusion targets to conditions where they will ignite and burn, liberating more energy than is required to initiate the fusion reactions. NIF experiments will allow the study of physical processes at temperatures approaching 100 million $\mathrm{K}$ and 100 billion times atmospheric pressure. These conditions exist naturally only in the interior of stars and in nuclear weapons explosions. ${ }^{1-4}$

\section{NIF LASER SYSTEM ARCHITECTURE}

The National Ignition Facility is shown schematically in Figure 1. NIF's laser architecture and laser sub-systems have been described in detail elsewhere. ${ }^{5,6}$ NIF is a 192beam flashlamp-pumped neodymium-doped glass laser configured in a novel multi-pass master oscillator power amplifier (MOPA) system. The basic subsystems of NIF are the amplifier flashlamp power conditioning system, the injection laser system consisting of the master oscillator and high-gain preamplifier modules, the main laser system along with its optical components, the switchyards, and the target chamber and its experimental systems. The entire laser system, switchyards, and target area is housed in an environmentally controlled building. An 


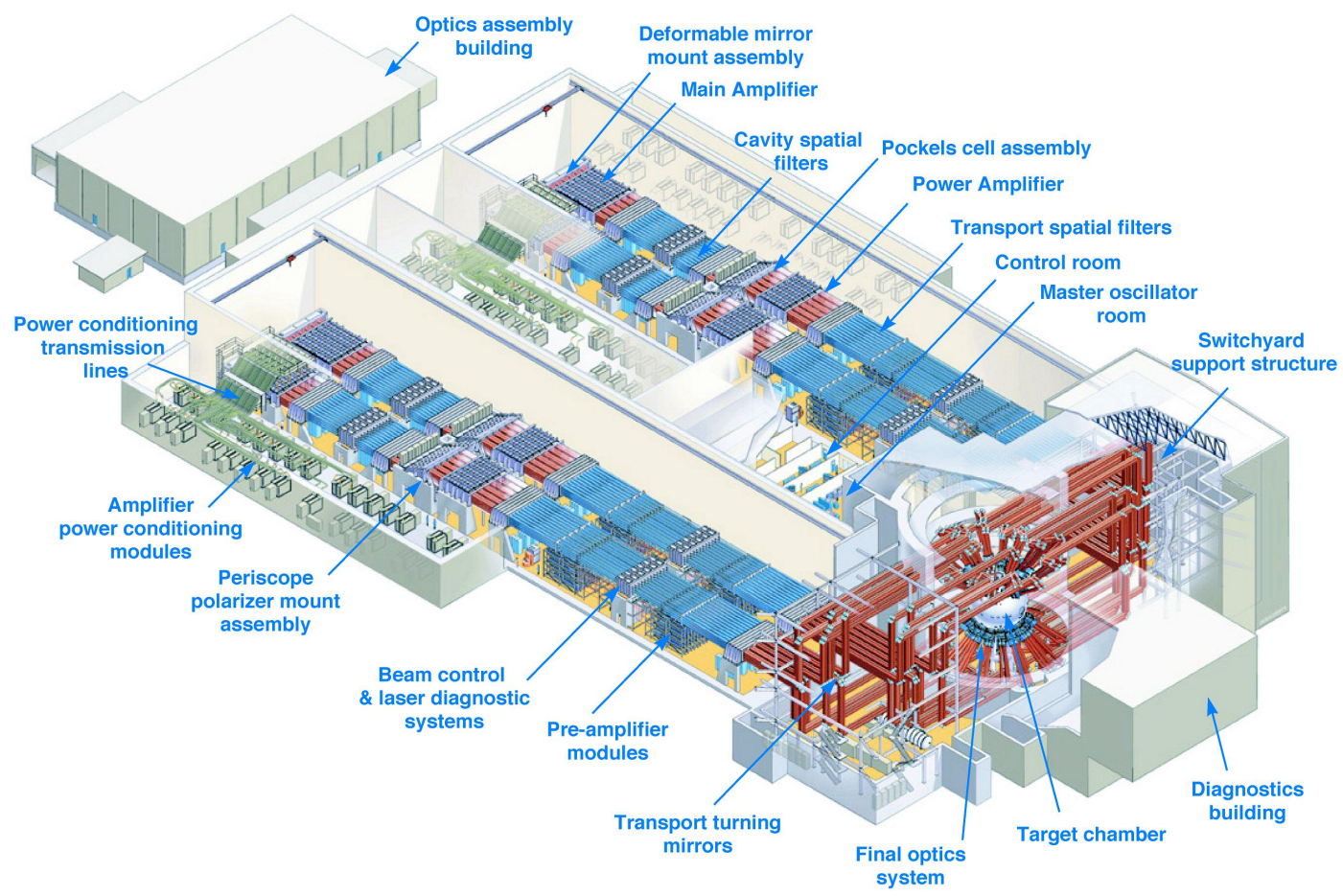

Fig. 1. Schematic view of the National Ignition Facility showing the main elements of the laser system. The 10-meter diameter target chamber sets the scale for the facility.

integrated computer control system monitors, aligns, and operates the more than 60,000 control points required for NIF's operation. A large cleanroom facility, the Optics Assembly Building, is located at one end of NIF for assembling and installing the precision optical and optomechanical components that make up the NIF laser system. On the opposite end of the facility the Diagnostics Building houses experimenters, data acquisition systems, and target preparation and storage areas Over 3,000 $46 \mathrm{~cm}$ x $81 \mathrm{~cm} \mathrm{x} 4.1 \mathrm{~cm}$ glass slabs illuminated by 7,600 2-meter long flashlamps comprise NIF's large amplifier systems. More than 7,500 meter-scale and 26,000 smaller optics are used in NIF for a total area of precision optical surfaces of nearly 1 acre $\left(\sim 4,000 \mathrm{~m}^{2}\right)$. These optics are assembled into thousands of precision cleaned and aligned line-replaceable units (LRUs) that form each beam line.

A key component in each laser beamline is a plasmaelectrode Pockels cell (PEPC), utilizing potassium dihydrogen phosphate (KDP) plates, which acts as an optical switch. When combined with a polarizer, the PEPC allows light to pass through or reflect off the polarizer. The PEPC thus traps the laser light between two mirrors as it makes four one-way passes through the main amplifier system before being switched out to continue its way to the target chamber.
NIF's laser system architecture was developed following nearly three decades of experience building large lasers for the U.S. Inertial Confinement Fusion (ICF) Program. ${ }^{3}$ Experience gained with earlier laser systems at LLNL, e.g., the Shiva $10 \mathrm{~kJ}$ infrared laser ${ }^{7}$ and the Nova $30 \mathrm{~kJ}$ ultraviolet laser ${ }^{8}$, allowed researchers to specify the requirements for the NIF laser architecture.

These requirements were driven in part by studies carried out in the late 1980's and early 1990's that specified the geometric symmetry and amount of laser drive energy needed to uniformly compress, initiate and sustain fusion reactions in spherical deuterium-tritium filled targets using the indirect drive process, which is described below.

These requirements taken together with advances in laser technology, including optics and electro-optical systems led to the NIF Conceptual Design Report (CDR) in 1994. ${ }^{9}$ During initial operation, NIF is configured to operate in the "indirect drive" configuration, which directs the laser beams into cones in the upper and lower hemispheres of the target chamber. This configuration is optimized for illuminating the fusion capsule mounted inside cylindrical hohlraums using $\mathrm{x}$-rays generated from the hot walls of the hohlraum to implode the capsule. ${ }^{10}$ 

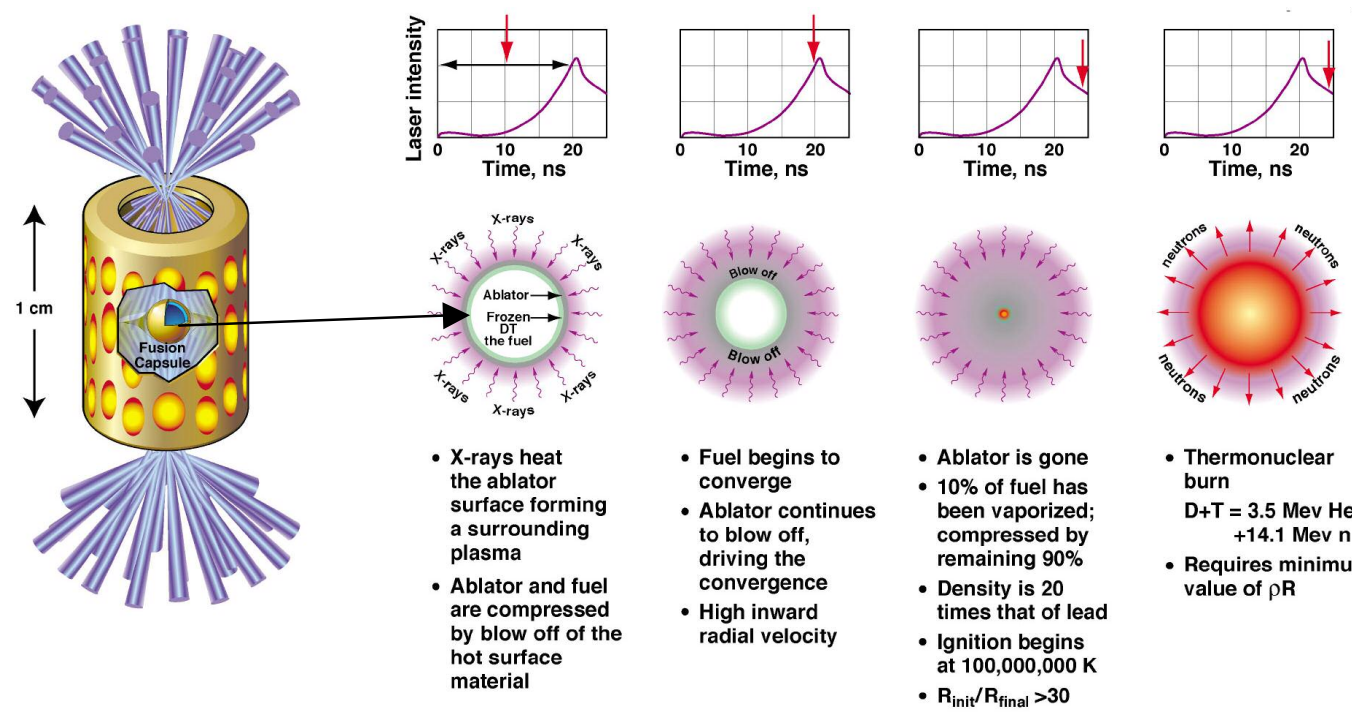
- Thermonuclear
burn
$\mathrm{D}+\mathrm{T}=3.5 \mathrm{Mev} \mathrm{He}$ +14.1 Mev $\mathrm{n}$
- Requires minimum
value of $\rho \mathbf{R}$

Fig. 2. A schematic representation of a NIF indirect-drive hohlraum target is shown on the left. NIF's 192 laser beams are grouped in 48 "quads" of four laser beams that are directed in opposite ends of the hohlraum to produce the x-ray drive. The time sequence on the right shows how the $\mathrm{x}$-rays interact with the fusion capsule to create ignition and burn with energy gain.

In this design, NIF laser beams are directed in an 8-fold symmetry around the azimuth of the target chamber and arranged in three cones of beams. For inertial fusion studies the beams will deliver 1.8 million joules (approximately 500 trillion watts of power) in a specially shaped pulse of laser energy in the near-ultraviolet (351 nanometer wavelength). The pattern of illumination in the hohlraum target and the sequence of ignition are shown in Figure 2. The energy available on NIF is approximately 60 times the energy of the Nova laser, which was operated at LLNL between 1983 and 1999 and currently operating 60-beam Omega Laser at the University of Rochester's Laboratory for Laser Energetics (LLE). ${ }^{11}$

\section{NIF EARLY LIGHT}

In early 2001, the NIF Project team embarked on an ambitious plan to install, commission, and activate a "quad" of four laser beam lines as early as possible, consistent with approved high-level Project cost and schedule milestones. This program, known as NIF Early Light or NEL, required completion of a significant amount of the NIF laser system and associated infrastructure in order to be successful. This included completion, commissioning, and activation of the entire NIF conventional facility, one of NIF's two 10-story tall optical switchyards with beam transport optics, the 10-meter diameter target chamber and its support systems, one of NIF's two laser bays, one cluster ( 48 beams) of laser system support utilities, one bundle ( 8 beams) of flashlamps and power conditioning modules, and one preamplifier module feeding a quad of laser beams. In addition, the Master Oscillator Room, the Integrated Computer Control System, the Optics Assembly Building, LRU transport and handling systems, and laser and target diagnostics systems had to be installed, commissioned and available for NEL.

In October 2001, the first laser light from NIF's master oscillator was generated in the master oscillator room. This master oscillator has demonstrated the required pulse shaping stability and accuracy for high contrast ignition pulses and other types of laser pulses that are of interest to NIF experimenters. In June 2002, the first preamplifier module was installed in the Laser Bay and routinely amplifies master oscillator pulses to the joule level. In April 2003, all 192 beampath enclosures were completed and ready for optics installation.

The first high energy third harmonic, or $3 \omega$, laser light to the center of NIF's target chamber was achieved in January 2003 with approximately 1 kilojoule $(\mathrm{kJ})$ of laser energy focused onto a simple foil target. The energetic $\mathrm{x}$ rays emitted from this target were measured with an x-ray pinhole imaging system mounted on the target chamber. In April 2003, $10.6 \mathrm{~kJ}$ of $3 \omega$ light was produced in four beams and directed to a target in the target chamber. In late summer 2003, $16 \mathrm{~kJ}$ of $3 \omega$ light in four beams was delivered to the target chamber for experiments. Increasing energy $3 \omega$ shots are planned through 2004 culminating in a full energy shot with $40 \mathrm{~kJ}$ in a "quad" of four beams, thereby demonstrating NIF's maximum $3 \omega$ performance requirements in this configuration. 

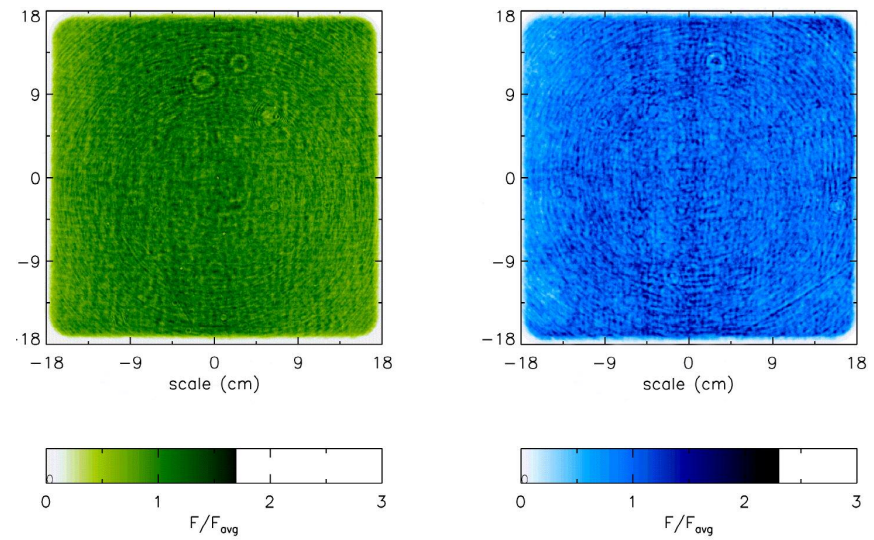

Fig. 3. Near field image of an $11.4 \mathrm{~kJ} 2 \omega$ (left) and $10.4 \mathrm{~kJ} 3 \omega$ (right) NIF beams showing excellent contrast uniformity, exceeding NIF's requirements.

A separate target chamber, known as the Precision Diagnostic System (PDS), which is located in one of NIF's switchyards, has also been used to fully characterize NIF's $1 \omega, 2 \omega$, and $3 \omega$ laser beam energy, power, and wavefront to validate and enhance computer models that predict laser performance. Any one of the four activated NIF beams can be directed into the PDS using a robotic mirror and transport system. Figure 3 shows examples of high-energy $2 \omega$ and $3 \omega$ beams imaged in the near field using the PDS.

NIF's highest $3 \omega$ single laser beam energy to date is $10.4 \mathrm{~kJ}$, equivalent to $2 \mathrm{MJ}$ for a fully activated NIF, exceeding the NIF energy point design of $1.8 \mathrm{MJ}$. This energy was achieved with $13.65 \mathrm{~kJ} 1 \omega$ drive in a $3.5 \mathrm{~ns}$ pulse. We have also conducted a series of shots generating green, or $2 \omega$, laser light with single beam energy up to $11.4 \mathrm{~kJ}$ in a $5 \mathrm{~ns}$ square pulse. This is equivalent to nearly 2.2 MJ on target for 192 beams. In July 2003, $26.5 \mathrm{~kJ}$ of $1 \omega$ light per beam was produced. This energy is $30 \%$ greater than the drive energy required for each NIF laser beam. NIF has now demonstrated the highest energy $1 \omega$, $2 \omega$, and $3 \omega$ laser beamlines in the world. High power campaigns have also been completed with drive power reaching 7 terawatts or about 5 gigawatts $/ \mathrm{cm}^{2}$. Figures 4 and 5 detail energy and power achieved on a number of shots conducted over the past year.

Beam-to-beam synchronization has also been measured and adjusted to better than 6 picoseconds, which corresponds to approximately 1 part in 150,000 of the total beampath in NIF. Complex shaped ignition pulses as well as ramped and flat-in-time pulses with multi-kJ energies and pulse lengths up to 25 ns have also been demonstrated.

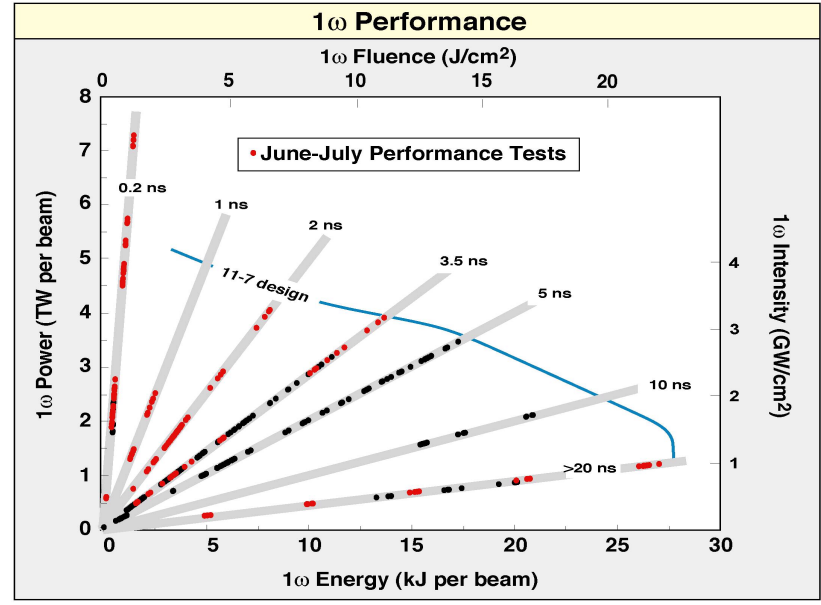

Fig. 4. $1 \omega$ energy vs. power is plotted for a number of NIF performance shots. The plot also indicates the level where energy and power is limited by the available number of glass slabs in the main amplifier (11 slabs) and the power amplifier ( 7 slabs).

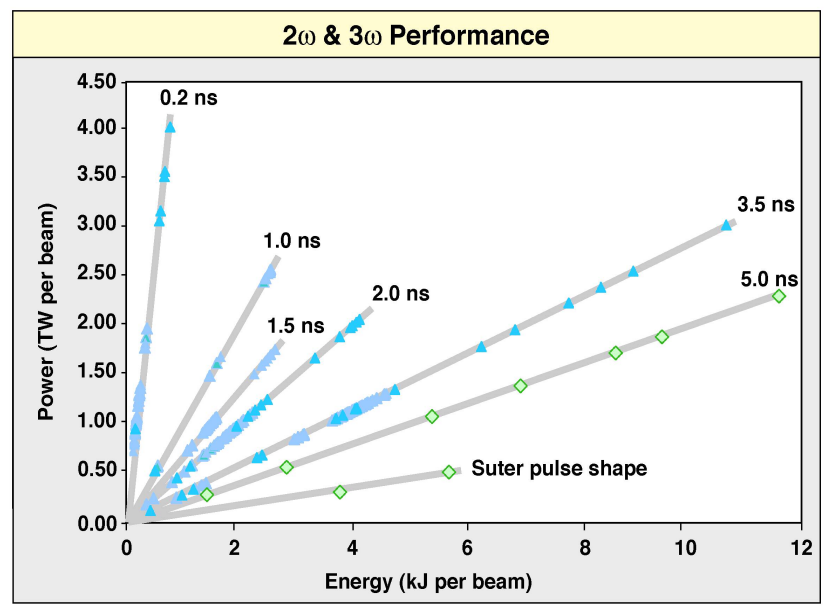

Fig. 5. $2 \omega$ (triangles) and $3 \omega$ diamonds) energy vs. power is plotted for a number of NIF performance shots, including $2 \omega$ shaped ignition pulses (Suter pulse).

Table 1 summarizes NIF's laser performance to date in terms of its 96-beam or 8-beam completion criteria, which are the high-level requirements that the Project must meet to be successful. By these standards, NEL has demonstrated nearly all the completion criteria for NIF. The remaining criterion having to do with pulse dynamic range is close to the final requirement and will be met in the coming year.

The NEL Program has been extremely successful. To date over 300 full laser system shots have been conducted with approximately 200 shots for laser system commissioning and performance tests and 100 shots for diagnostic systems commissioning and physics experiments. The experience gained from NEL has been very important for 


\begin{tabular}{|c|c|c|c|c|}
\hline Specification & $\begin{array}{l}96 \text { Beam } \\
\text { 'erformance } \\
\text { lequirement }\end{array}$ & \begin{tabular}{||c}
96 Beam \\
Performance \\
Measured on \\
NEL
\end{tabular} & $\begin{array}{l}\text { ingle Bundle } \\
\text { (8 Beam) } \\
\text { 'erformance } \\
\text { lequirement }\end{array}$ & $\mid \begin{array}{c}\text { Single Bundle } \\
\text { Performance } \\
\text { Measured on } \\
\text { NEL }\end{array}$ \\
\hline $\begin{array}{l}\text { Pulse En- } \\
\text { ergy }\end{array}$ & $500 \mathrm{~kJ}$ & $1000 \mathrm{~kJ}$ & $75 \mathrm{~kJ}$ & $83 \mathrm{~kJ}$ \\
\hline Peak Power & 200 TW & $400 \mathrm{TW}$ & $21 \mathrm{TW}$ & $32 \mathrm{TW}$ \\
\hline Wavelength & $.35 \mu \mathrm{m}$ & $\begin{array}{c}.35 \mu \mathrm{m} \text { and } \\
.53 \mu \mathrm{m}\end{array}$ & $.35 \mu \mathrm{m}$ & $\begin{array}{c}.35 \mu \mathrm{m} \text { and } \\
.53 \mu \mathrm{m}\end{array}$ \\
\hline $\begin{array}{l}\text { Positioning } \\
\text { Accuracy }\end{array}$ & $\begin{array}{l}00 \mu \mathrm{m} \text { rms : } \\
\text { target plane }\end{array}$ & $59 \mu \mathrm{m}$ & $100 \mu \mathrm{m}$ & $59 \mu \mathrm{m}$ \\
\hline $\begin{array}{l}\text { Pulse Dura- } \\
\text { tion }\end{array}$ & $20 \mathrm{~ns}$ & $0.2-23 \mathrm{~ns}$ & $20 \mathrm{~ns}$ & $0.2-23 \mathrm{~ns}$ \\
\hline $\begin{array}{l}\text { Pulse Dy- } \\
\text { namic } \\
\text { Range }\end{array}$ & $>25: 1$ & $22: 1$ & $50: 1$ & 22:1 \\
\hline $\begin{array}{l}\text { Pulse Spot } \\
\text { Size }\end{array}$ & $600 \mu \mathrm{m}$ & $\begin{array}{c}140 \mu \mathrm{m}- \\
600 \mu \mathrm{m}\end{array}$ & $600 \mu \mathrm{m}$ & $\begin{array}{c}140 \mu \mathrm{m}- \\
600 \mu \mathrm{m}\end{array}$ \\
\hline $\begin{array}{l}\text { Pre-pulse } \\
\text { power }\end{array}$ & $<108 \mathrm{~W} / \mathrm{cm}$ & $\ll<10^{8} \mathrm{~W} / \mathrm{cm}^{2}$ & $4 \times 10^{6} \mathrm{~W} / \mathrm{cr}$ & $\begin{array}{c}<<4 \times 10^{6} \\
\mathrm{~W} / \mathrm{cm}^{2}\end{array}$ \\
\hline Cycle Time & $\begin{array}{l}8 \text { hours ma) } \\
\text { between full } \\
\text { system shot: }\end{array}$ & $<4 h$ & $\begin{array}{l}8 \text { hours ma) } \\
\text { between ful } \\
\text { system shot }\end{array}$ & $<4 h$ \\
\hline
\end{tabular}

Table 1. NIF 96 beam and 8-beam bundle performance requirements compared to those achieved on NEL.

reaching final engineering designs for the production of the remainder of NIF. Effort is now focused on incorporating design enhancements that increase NIF's performance and reliability while minimizing production costs and longer-term operating costs.

\section{NIF TARGET EXPERIMENTAL SYSTEMS}

The NIF target area includes the 10-meter diameter high-vacuum target chamber. The target chamber contains the laser entry ports as well as over 100 ports for diagnotic instrumentation and target insertion. Each laser entry port allows a quad of laser beams to be focused to the center of the target chamber through a final optics assembly (FOA) containing optics to provide a variety of beam profiles on target, KDP and deuterated KDP plates to convert the infrared laser light into the ultraviolet, the final focus lens, debris shields and vacuum gate valve for each beam.

Figure 6 shows the NIF target chamber at the "equator" level where the target diagnostics will be fielded for experimental commissioning. Diagnostics can be located in a variety of positions but typically will be placed around the equator of the target chamber or near the top pole. These include static and gated $\mathrm{x}$-ray imaging and streak cameras, laser backscatter diagnostic systems, and a laser interferometer system for measuring shock velocities. This level also contains the Target Alignment Sensor Positioning System, the Target Positioning System, and the Chamber Center Reference System.

The first physics experiments began on NIF in $\mathrm{Au}-$ gust 2003. Initial experiments studied laser-plasma interactions that are important for understanding the propagation of laser beams and the delivery of energy into ignition hohlraums. Figure 7 shows results from a recent experiment directing NIF's first four beams with $16 \mathrm{~kJ}$ of ultraviolet light into a gas-filled target. The x-ray images compare favorably with sophisticated calculations of laser-plasma interactions. ${ }^{12}$

Other experiments are studying hydrodynamics of materials subjected to laser-driven shocks. Figure 8 shows a radiograph of the hydrodynamics of a shocked aluminum jet impinging on low-density carbon foam. In this experiment, two of NIF's laser beams were used to drive the experiment and two other beams, delayed in time, were directed to off-center vanadium foils to provide energetic x-rays for point-projection backlighters. As more NIF beams become available, experimenters can continue these studies by inducing higher energy shocks in materials and can use additional backlighters with longer delays to study the further time evolution in these types of experiments.

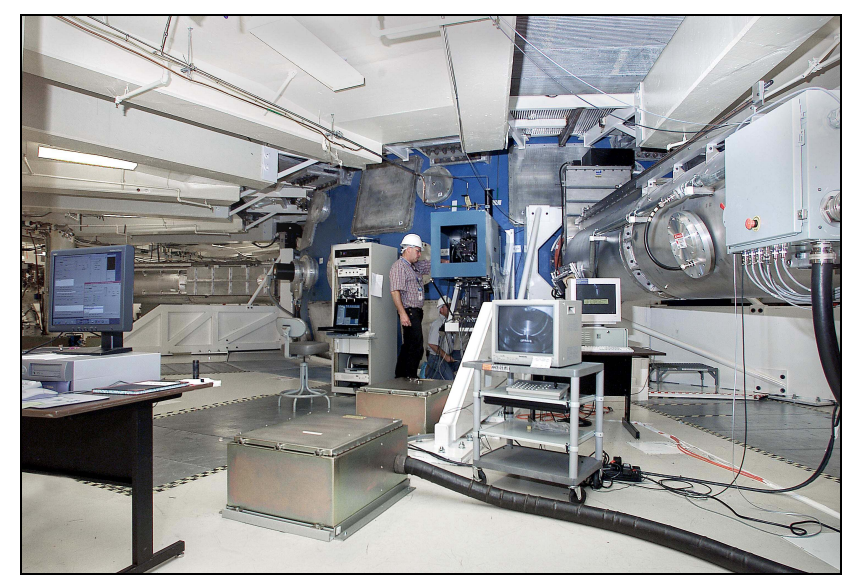

Fig. 6. View of NIF Target Chamber at the equator level. Visible in this photograph are target positioning and alignment systems. 


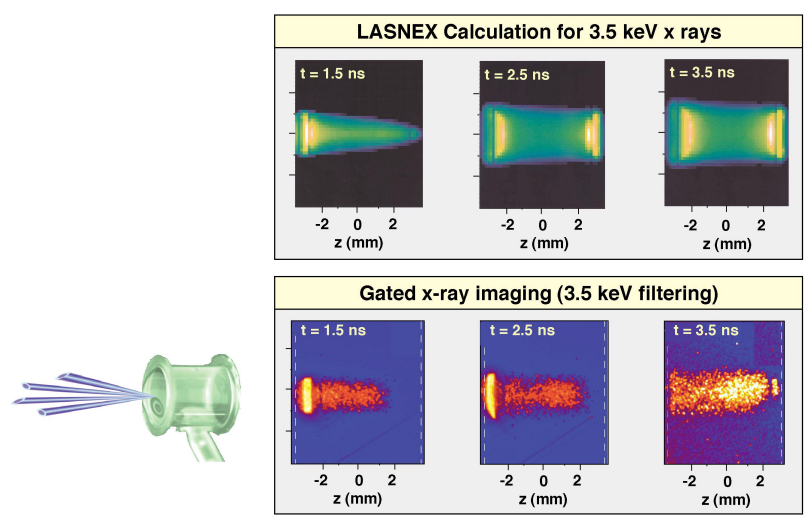

Fig. 7. Laser-plasma interaction experiments have been fielded on NIF using cm-scale $\mathrm{CO}_{2}$ gas-filled targets, shown on the left. Results from the first physics experiments on NIF using targets are shown on the right, which are images of x-ray emission using a gated x-ray imaging diagnostic at one ns intervals. The data on the bottom is compared with computer models above.
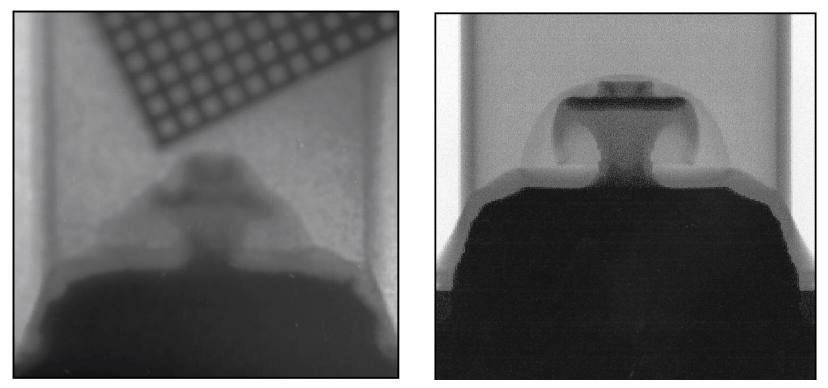

Fig. 8. X-ray radiograph (left) of a single-jet hydrodynamics experiment conducted on NIF taken approximately $15 \mathrm{~ns}$ after the main laser pulse. The diameter of the target is approximately $1 \mathrm{~mm}$. A highly supersonic jet of aluminum can be seen interacting with a low-density carbon foam. On the right, a computer simulation reproduces many of the features seen in the experiment. Two tailored NIF beams were used to drive this experiment from below, while the other beams provided separate, delayed x-ray backlighter sources.

\section{PROSPECTS FOR IGNITION ON NIF}

One of the key missions of NIF is to generate and study thermonuclear ignition and energy gain using the 192 lasers of NIF to compress and heat small capsules containing a mixture of the heavy hydrogen isotopes of deuterium and tritium. Figure 2 illustrated how indirect drive inertial confinement fusion is achieved using NIF. NIF fusion targets use carefully prepared spherical ignition capsules containing the fusion fuel in a thin, very smooth frozen layer surrounding a pressurized DT gas volume. The capsules are precisely formed plastic or graded copper-doped beryllium shells. The capsule is suspended in a hollow gold cylinder called a hohlraum with laser entrance windows on each end of the cylinder. Precisely focused temporally-shaped laser beams are di- rected into the hohlraum to the inside walls, generating intense $x$-rays that uniformly illuminate the capsule. The $\mathrm{x}$-rays ablate the outer surface of the capsule very rapidly. The reaction force from the ablation drives the fusion fuel inward, compressing and heating it to the conditions necessary for thermonuclear fusion reactions to self-initiate. Under the proper conditions, the thermonuclear reactions will propagate outward in a self-sustaining fusion burn, consuming all of the fuel and liberating more energy than was used to drive the target.

This type of ICF target is called an indirect-drive target because the laser beams are not incident directly on the fusion capsule. Indirect-drive targets are advantageous because they tend to smooth out imperfections in the laser drive energy and uniformity. However, indirect drive provides less efficient coupling of $\mathrm{x}$-ray energy to the fusion capsule. . $^{10,13}$

A second approach to ICF is direct drive, where lasers directly illuminate the fusion capsule. The 60-beam Omega laser at (LLE) is configured to study direct drive ICF and has been performing ignition experiments for many years. Together, LLE and NIF scientists and engineers have worked to design the NIF switchyards and target chamber to allow reconfiguration of some of its laser beams to a more symmetric arrangement for direct drive ignition studies in the future. ${ }^{14}$ Recent studies by LLE researchers are also looking at "polar" direct drive options, in which beam positioning and timing using NIF's indirect drive configuration of lasers can be optimized to directly drive fusion capsules. ${ }^{15}$

A NIF "point design" ignition hohlraum and capsule has been developed using increasingly sophisticated 3D computer calculations. The most recent calculations, shown in Figure 9, performed on one of LLNL's supercomputer systems indicates the production of over 20 Megajoules (MJ) of fusion yield for the nominal $1.8 \mathrm{MJ}$ of UV light delivered from the 192 laser beams. ${ }^{16}$
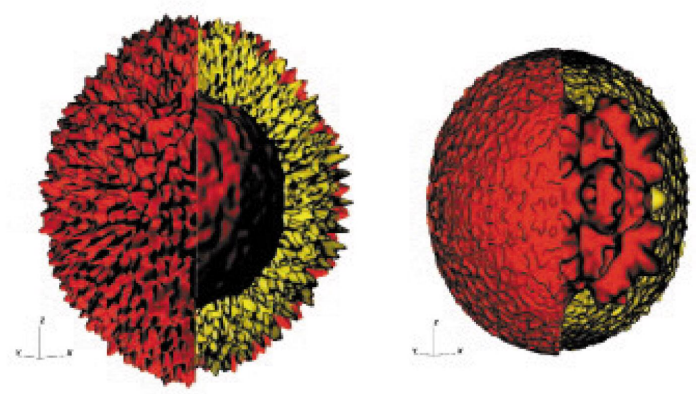

Fig. 9. 3-D calculation of capsule implosion showing predictions for a point-design NIF ignition target. The left figure shows the $100 \mu \mathrm{m}$ diameter, $60 \mathrm{~g} / \mathrm{cm}^{3}$ isodensity contour of the DT at maximum implosion velocity, $140 \mathrm{ps}$ before ignition time. On the right the $400 \mathrm{~g} / \mathrm{cm}^{3}$ DT is $50 \mu \mathrm{m}$ in diameter at ignition time. 
Prospects for ignition on NIF have improved significantly since the time of the NIF CDR. Designs supporting indirect-drive, or $\mathrm{x}$-ray drive of ignition capsules in hohraums are becoming more robust as better physics understanding and better modeling capability, including full 3-dimensional modeling of capsules and hohlraums, allows design trade-off studies to be rapidly performed and design spaces to be optimized. For example, optimization studies have improved plastic capsule performance by a factor of two while allowing ablator roughness to increase by a factor of two, easing fabrication requirements. ${ }^{16}$

New designs developed by researchers at Los Alamos National Laboratory (LANL) using beryllium with graded $\mathrm{Cu}$ dopant are particularly robust, with ablator roughnesses being relaxed by as much as a factor of 10-20 over previous designs and newly optimized polyimide designs, while still producing fusion ignition and energy gain. In addition, significant progress has been made at LANL and at LLE in fabricating smooth and beryllium/copper and plastic capsules that nearly meet these new design specifications. ${ }^{14,17}$

Precision control of cryogenic $\mathrm{D}_{2}$ ice smoothness using infrared heating in an isothermal hohlraum has now been demonstrated. ${ }^{18}$ Progress is also being made in developing cryogenic hohlraums with convection mitigation and thermal control. Diffusion filling of a capsule in a hohlraum has also been recently demonstrated and integration of infrared layering, thermal shimming, convection mitigation, and characterization in a $\mathrm{D}_{2}$ test system is under way.

Our increased understanding of fusion target physics and our enhanced computational capabilities are also allowing us to propose target designs that could significantly simplify the preparation and fielding of cryogenic targets on NIF. These designs include extremely narrow micron-diameter fill tubes and plastic or graded-dopant beryllium capsules that ease the filling and maintenence of cryogenic DT in the capsule. The fill tube does not significantly impact the implosion characteristics of the capsule based on recent calculations. Figure 10 shows a prototype target using this design. Cryogenic target positioning systems based on this design are currently being developed for use on NIF beginning in 2007 when sufficient beam energy and symmetry is first available.

Hohlraums driven with $2 \omega$ laser light from NIF are also actively being studied. ${ }^{19}$ Figure 11 shows recent calculations suggesting that as much as $1.5 \mathrm{MJ}$ of energy may couple to a capsule at $250-\mathrm{eV}$ drive temperature.
However, physical data on $2 \omega$ laser-plasma interactions (LPI) is limited and more work is needed. NIF $2 \omega$ oper-
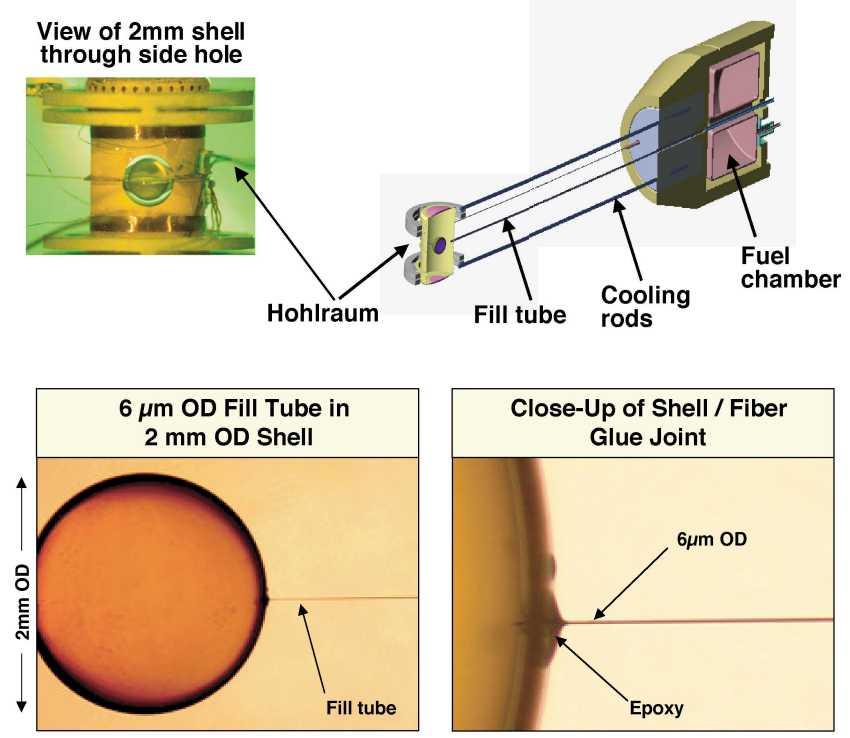

Fig. 10. Photograph of a fill-tube fusion capsule mounted in a hohlraum and CAD representation of the cryogenic target and target holder (top). Other photos show close-ups of the micronsized fill tube attached to the capsule.

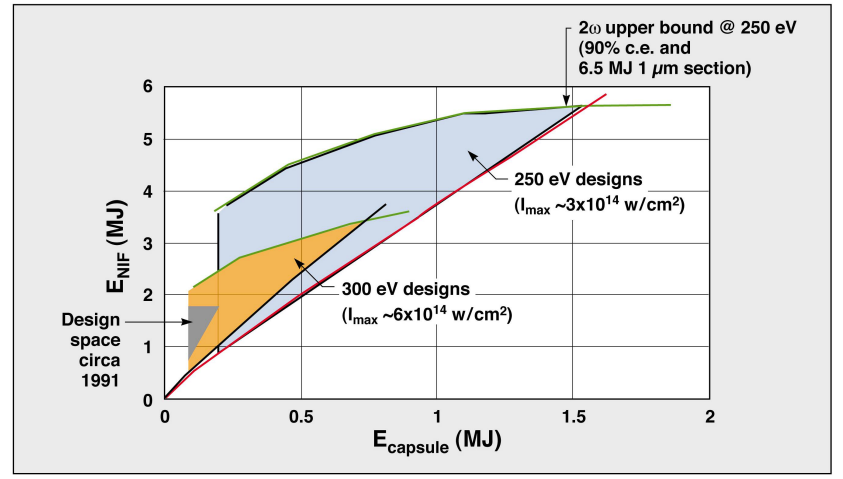

Fig. 11. Recent calculations of energy coupled to a fusion capsule from $\mathrm{X}$ rays converted when the laser energy is incident on the hohlraum walls. NIF's design space, as calculated in 1991 during the conceptual design phase of the project, is shown in the lower left of the figure. Recent improvements in modeling and physics understanding lead to a significantly increased design space for $2 \omega$ laser drive. Two extended regions in the figure show that hohlraums can be driven to temperatures of $250 \mathrm{eV}$ and $300 \mathrm{eV}$, indicating that as much as 1.5 Megajoules of $\mathrm{x}$-ray drive energy may couple to a capsule at $250 \mathrm{eV}$.

ation has been demonstrated and we are studying how to configure some of NIF's early beams for high-energy $2 \omega$ LPI studies.

Finally, fast ignition experiments using the Gekko Laser at the University of Osaka, Institute for Laser Engineering, and the Vulcan Laser at Rutherford Appleton 
Laboratory in the UK are providing tantalizing glimpses of low-energy symmetric heating combined with highpower asymmetric drive to induce possible hot-spot ignition conditions in cone-focused targets. ${ }^{20-22}$

A "proof-of-principle" NIF fast-ignition experiment is in the design phase. Laser physicists have determined how NIF's injection laser, main amplifier, and beam transport system could be modified to allow up to 20 high-energy petawatt-class (HEPW) beams to be directed to target chamber center. Initial experiments are being designed to utilize a single kilojoule HEPW beam line with 1-30 picosecond pulse width to drive electron or proton cone-focused ignition experiments. Initial shortpulse capability on NIF is planned to be in place in the 2006 time frame. Additional HEPW beams in a quad could be installed to provide multi-kilojoule capability. ${ }^{23}$

\section{THE PATH FORWARD TO FULL NIF}

Completion of all 192 laser beams is scheduled for September 2008. We have developed a plan for beam deployment that supports experiments with steadily increasing capability. We are preparing to commence the build-out of the rest of the laser system beginning in FY 2005. The increasing symmetry and energy available as the number of beams increases enables a variety of target configurations including planar targets, horizontal and vertical half-hohlraums (halfraums), and vertical hohlraums with 4-fold and 8-fold symmetry. After project completion, NIF is expected to ramp up to approximately 700 shots per year for a wide variety of experimental users as a national user facility. A shot campaign conducted on NIF in 2003 provided three target shots per day over a three-day period, giving us confidence in NIF's ability to meet the planned 700 shots per year when it is fully operational. We have also developed a plan for fielding facility diagnostics that is synchronized to the increasing capability NIF provides.

In addition to diagnostics, the NIF Program includes support for building and commissioning facility capabilities in diffractive optics (phase plates), cryogenic target systems, and target area operations. We are also developing a non-ignition cryogenic target capability to be fielded around the time of first cluster of 48 beams.

As NIF matures, we fully expect the facility to evolve to include exciting new capabilities, some of which are mentioned briefly here. The NIF laser system and support buildings have been designed with maximum flexibility for future enhancements such as multi-wavelength operation and high-energy short-pulse operation. NIF is ready to deliver the next generation of HED and ICF experimental capability for the US and international mental capability for the US and international scientific communities. $^{\dagger}$

\section{ACKNOWLEDGMENTS}

The authors would like to express their appreciation to the many people, institutions, and industrial partners that are diligently working to provide the National Ignition Facility for our nation. This work was performed under the auspices of the U.S. Department of Energy by the University of California, Lawrence Livermore National Laboratory under contract W-7405-Eng-48.

\section{REFERENCES}

1. J. LINDL, Inertial Confinement Fusion: The Quest for Ignition and Energy Gain Using Indirect Drive, Springer-Verlag, New York (1998).

2. "Laboratory Microfusion Capability Phase-II Study," prepared by Interscience, Inc. for the Inertial Fusion Division Office of Research and Advanced Technology, ISI-TM9005281, May 31, 1990.

3. W. F. KRUPKE, ed. "Solid State Lasers for Application to Inertial Confinement Fusion (ICF)," Proc. SPIE Vol. 2633 (1995).

4. C. B. TARTER, "Inertial Fusion and Higher Energy Density Science in the United States," Proc. 2001 Conf. On Inertial Fusion Science and Applications (IFSA 2001), K. A. Tanaka, D. D. Meyerhofer, J. Meyer-ter-Vehn, eds., Elsevier (2002).

5. E. MOSES et al., "The National Ignition Facility: Status and Plans for Laser Fusion and High-EnergyDensity Experimental Studies," Fusion Science and Technology, Vol. 43, 420 (2003).

6. M. A. LANE, C. R. WUEST, eds., "Optical Engineering at the Lawrence Livermore National Laboratory II: The National Ignition Facility," Proc. SPIE Vol. 5341 (2004).

7. P. COYLE, ed., "Shiva Laser System," 1976 Laser Program Annual Report, Lawrence Livermore National Laboratory, UCRL-50021-61, 2-54 - 2-183 (1976).

8. W. SIMMONS and R. GODWIN, "Nova Laser Fusion Facility - Design, Engineering, and Assembly Overview," Nucl. Technol./Fusion Vol. 4, 8-24 (1983).

9. J. PAISNER et al., "Conceptual Design of the National Ignition Facility," First International Conference on Solid State Lasers for Application to Inertial Confinement Fusion, Proc. SPIE Vol. 2633, 2 (1995).

\footnotetext{
${ }^{+}$For more information on the NIF Project visit our web site at http://www.llnl.gov/nif
} 
10. J. LINDL, "Development of the Indirect-Drive Approach to Inertial Confinement Fusion and the Target Physics Basis for Ignition and Gain," Phys. Plasmas Vol. 2(11), 3933-4024 (1995).

11. T. R. BOEHLY et al., "The Upgrade to the OMEGA Laser System," Rev. Sci. Instr. Vol 66(1), 508-510 (1995).

12. S. GLENZER et al., "Progress in Long Scale Length Laser-Plasma Interactions," Inertial Fusion Sciences and Applications 2003, B. A. Hammel, D. D. Meyerhofer, J. Meyer-ter-Vehn, H. Azechi, eds., American Nuclear Society, Lagrange Park, 207-212 (2004).

13. S. HAAN, et al., "Update On Target Design for the National Ignition Facility," Proc. 2001 Conf. On Inertial Fusion Science and Applications (IFSA 2001), K. A. Tanaka, D. D. Meyerhofer, J. Meyerter-Vehn, eds., Elsevier (2002).

14. R. MCCRORY, "Progress in Inertial Confinement Fusion Research in the United States," Inertial Fusion Sciences and Applications 2003, B. A. Hammel, D. D. Meyerhofer, J. Meyer-ter-Vehn, H. Azechi, eds., American Nuclear Society, Lagrange Park, 3-8 (2004).

15. S. SKUPSKY et al., "Advanced Direct-Drive Target Designs for the NIF," Inertial Fusion Sciences and Applications 2003, B. A. Hammel, D. D. Meyerhofer, J. Meyer-ter-Vehn, H. Azechi, eds., American Nuclear Society, Lagrange Park, 61-64 (2004).

16. S. HAAN et al., "Update on Indirect Drive Ignition Target Designs for NIF," Inertial Fusion Sciences and Applications 2003, B. A. Hammel, D. D. Meyerhofer, J. Meyer-ter-Vehn, H. Azechi, eds., American Nuclear Society, Lagrange Park, 55-60 (2004).

17. A. NOBILE et al., "Development of BerylliumCopper Alloy Ignition Capsules," Inertial Fusion Sciences and Applications 2003, B. A. Hammel, D. D. Meyerhofer, J. Meyer-ter-Vehn, H. Azechi, eds., American Nuclear Society, Lagrange Park, 753-757 (2004).

18. B. KOZIOZIEMSKI et al., "Demonstration of Symmetry Control of Infrared Heated Deuterium Layers in Hohlraums," Inertial Fusion Sciences and Applications 2003, B. A. Hammel, D. D. Meyerhofer, J. Meyer-ter-Vehn, H. Azechi, eds., American Nuclear Society, Lagrange Park, 762-765 (2004).

19. L. SUTER, "Prospects for High-gain, High-yield NIF Targets Driven by $2 \omega$ Light," Inertial Fusion Sciences and Applications 2003, B. A. Hammel, D. D. Meyerhofer, J. Meyer-ter-Vehn, H. Azechi, eds., American Nuclear Society, Lagrange Park, 23-34 (2004).
20. K. MIMA et al., "Recent Progress of Implosion Experiments with Uniformity-improved GEKKO XII Laser Facility at the Institute of Laser Engineering, Osaka University," Phys. Plasmas, Vol. 3(5), 2077 2083 (1996).

21. R. KODAMA et al., "Fast Heating With a Petawatt Laser as a Step to Ignition," Inertial Fusion Sciences and Applications 2003, B. A. Hammel, D. D. Meyerhofer, J. Meyer-ter-Vehn, H. Azechi, eds., American Nuclear Society, Lagrange Park, 333-338 (2004).

22. R. EDWARDS et al., "Experimental Investigation of the Transport of Electron Beams Generated by the Vulcan Petawatt Laser," Inertial Fusion Sciences and Applications 2003, B. A. Hammel, D. D. Meyerhofer, J. Meyer-ter-Vehn, H. Azechi, eds., American Nuclear Society, Lagrange Park, 344-348 (2004).

23. C. P. J. BARTY et al., "Technical Challenges and Motivations for High Energy Petawatt Lasers on NIF," Inertial Fusion Sciences and Applications 2003, B. A. Hammel, D. D. Meyerhofer, J. Meyerter-Vehn, H. Azechi, eds., American Nuclear Society, Lagrange Park, 612-615 (2004). 